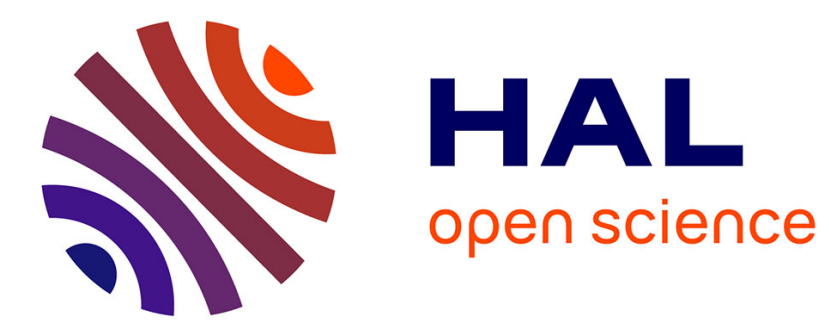

\title{
Blockchain as Schumpeter Mark 1 or Mark 2? An empirical analysis of blockchain job offers in France and Germany
}

Martin Cimiterra, Jackie Krafft, Lionel Nesta

\section{- To cite this version:}

Martin Cimiterra, Jackie Krafft, Lionel Nesta. Blockchain as Schumpeter Mark 1 or Mark 2? An empirical analysis of blockchain job offers in France and Germany. Industrial and Corporate Change, 2021, 30 (6), pp.1388-1402. 10.1093/icc/dtab009 . halshs-03162880

\section{HAL Id: halshs-03162880 \\ https://shs.hal.science/halshs-03162880}

Submitted on 12 Jan 2022

HAL is a multi-disciplinary open access archive for the deposit and dissemination of scientific research documents, whether they are published or not. The documents may come from teaching and research institutions in France or abroad, or from public or private research centers.
L'archive ouverte pluridisciplinaire HAL, est destinée au dépôt et à la diffusion de documents scientifiques de niveau recherche, publiés ou non, émanant des établissements d'enseignement et de recherche français ou étrangers, des laboratoires publics ou privés. 


\title{
Blockchain as Schumpeter Mark 1 or Mark 2? An empirical analysis of blockchain job offers in France and Germany
}

\author{
Martin Cimiterra ${ }^{1}$, Jackie Krafft ${ }^{1}$, Lionel Nesta ${ }^{1,2,3}$ \\ ${ }^{1}$ Université Côte d'Azur, CNRS, GREDEG (France) \\ ${ }^{2}$ OFCE SciencesPo Paris (France) \\ ${ }^{3}$ SKEMA Business School, France
}

\begin{abstract}
This paper investigates whether blockchain technology corresponds to Schumpeter Mark 1 or Schumpeter Mark 2 industrial dynamics. Using an original database of 385 job offers in three different domains, namely, blockchain, biotechnology and storekeeping, posted by 285 companies in France and Germany in early 2019, we explore whether the usual Schumpeter Mark 1 and 2 attributes apply to blockchains. We use ordered multinomial probit models to explain the level of work experience demanded by companies. To our knowledge, this contribution is one among very few attempts to identify the main features of blockchain industrial dynamics.
\end{abstract}

Key words: blockchain, Schumpeter Mark 1, Schumpeter Mark 2, innovation, technology, firms, jobs, skills

JEL Codes: 014, 016, 031, 032, O33

Acknowledgements: This work has been supported by the French government through UCA JEDI investments in future projects managed by the National Research Agency (ANR), under reference number ANR-15-IDEX-01. 


\section{Blockchain as Schumpeter Mark 1 or Mark 2? An empirical analysis of blockchain job offers in France and Germany}

\section{Introduction}

The increasing use of advanced digital technologies is transforming innovation and production activities (Alcacer et al., 2016); it is both creating and destroying jobs by changing skill requirements and firms' recruitment patterns, rendering some existing firm skills potentially redundant or obsolete (Autor, 2015; Autor and Dorn, 2013). The new digital paradigms include a broad range of new systemic technologies, such as blockchain, additive manufacturing, virtual reality, augmented reality, cloud computing, massive data analysis, artificial intelligence, connected objects, etc. (Rindfleisch et al., 2017). Despite the many academic studies of industrial dynamics and occupations and skills in the Information and Communication Technology (ICT) adoption literature (Autor et al., 1998; Antonelli et al., 2006), the potential impact of these new paradigms on the dynamics of innovation, production and skills has yet to be fully exploited (Consoli et al., 2016). There is a growing stream of work on blockchain (Böhme et al., 2015), related to the pro- or anti-competitive effects of platforms (Cong and He, 2019; Catalini and Gans, 2016), the changes that can be expected to corporate governance (Yermack, 2017), and blockchain as an institution allowing new forms of innovative coordination (Davidson et al., 2018). However, new jobs and skills associated to use of blockchain have been rather overlooked and highlights the need for studies focusing on the industrial dynamics associated to this new technology. 
The present contribution is an exploratory study of the link between disruptive technologies and the demand for skills. Demand for new skills is exploited to capture the industrial dynamics underlying the digital economy-and specifically blockchain which is considered a disruptive technology. Previous research has examined how the ICT/digital revolution has changed the management and organization of firms' innovation and production activities (Brynjolfsson and McAfee, 2014; Varian, 2018). Several authors have investigated differences related to the requirement for new digital skills (Spitz-Oener, 2006; Acemoglu and Autor, 2012; Nedelkoska and Quintini, 2017) and the expected impact on labour markets (Acemoglu and Restrepo, 2017; Atalay et al., 2018). In the present paper we address a series of issues which have been rather ignored in the literature. For instance, we are interested in the blockchain skills being sought by recruiters in the job market, the qualifications and experience expected of potential hires, which companies and sectors are recruiting, and is blockchain recruitment confined mostly to metropolitan areas or is it distributed across space.

Both academic and non-academic publications suggest that the development of blockchain corresponds more to a Schumpeter Mark 1 than a Schumpeter Mark 2 model (for basic characteristics of each model, see Dosi, 1982 and Marlerba and Orsenigo, 1995, 1997). In the extant literature cited above, blockchain is seen as a disruptive technology (promoting a creative destruction), and blockchain jobs as requiring highly qualified computer scientists and cryptographers, involving young and small new companies (start-ups) operating mostly in the financial sector, and likely to be geographically concentrated in large metropolitan areas. 
Our aim is to understand whether blockchain follows a Schumpeter Mark 1 or Mark 2 industrial dynamics profile, by providing evidence on blockchain job offers in France and Germany. To the best of our knowledge, none of the existing datasets capture the industrial dynamics of blockchain, which required us to develop an original database. We collected data from the online platform Glassdoor, which is one of the top blockchain employment recruitment websites. The blockchain job offers posted online provide detailed information on firms' identities and recruitment profiles and allow international and sectoral comparison. Our empirical strategy relies on assessing whether blockchain industrial dynamics fits within a Schumpeter Mark 1 or a Mark 2 evolution. Our overall objective is to investigate the expected economic impact of blockchain by identifying the main features of its industrial dynamics - specifically with the key entry of blockchain jobs and skills.

The article is structured as follows. Section 2 provides a literature review that gathers various strands of work: the academic, government and industry blockchain literature, on the one hand, and Schumpeter Mark 1 and Mark 2 developments, on the other hand. Section 3 presents the data and empirical methodology. Section 4 discusses the results and Section 5 concludes the paper.

\section{Literature review and framework}

\subsection{Blockchain literature}

Blockchain is probably one of the least documented technologies in the new digital paradigms so far. The Web of Science (WOS), which includes social science research, reports the following publications figures for 2019: 92,039 articles on artificial intelligence, 27,304 on virtual reality, 20,651 on cloud computing, 11,501 on massive data, 11,088 on the 
Internet of things, 6,981 on augmented reality, 4,203 on additive manufacturing and 1,800 on blockchain. If we look only at work in the fields of economics and management, blockchain is ranked sixth for number of published papers (with 1,411), ahead of additive manufacturing (902) and augmented reality (687), but behind artificial intelligence $(5,280)$, cloud computing $(3,375)$, virtual reality $(3,034)$, the Internet of things $(1,930)$ and massive data $(1,638)$. Among these 1,411 papers, most belong to the Information Technology (IT) systems and management fields and employ very specific approaches and methodologies. This strand of work visualizes the future Internet as a set of decentralized networks and as extending beyond the area of business finance and a focus essentially on Bitcoin cryptocurrency, to potential implementations in fields such as education, voting systems, transport, energy, health, Industry 4.0, the environment and sustainability. Despite their IT orientation, these papers converge on the new challenges being posed by smart contracts for legal systems and business models, and highlight the need for future research to focus on the rupture with the current state of the art.

Although the stream of work on blockchain in the core field of economics and management literatures is small, most academic contributions agree that blockchain is a paradigmatic example of a disruptive technology. Böhme et al. (2015) argue that blockchain's decentralized characteristics have the potential to disrupt payment and even monetary systems (central banks), which calls for research to identify the risks and regulatory issues involved. Yermack (2017) sees blockchain as an alternative to traditional financial ledgers, which could reduce transaction costs, increase liquidity and enable more accurate recordkeeping. This is expected to generate greater transparency and, eventually, change in the balance of power among managers, shareholders (both large institutional investors and small shareholders), auditors and other stakeholders involved in corporate governance. 
Cong and He (2019) and Catalini and Gans (2016) see blockchain as challenging the revenue models of incumbent firms due to the increased competition, lower privacy risks and joint investment in shared infrastructures it will facilitate. These advantages could provide new blockchain technology holders with more profitable market entry and market penetration based on initial coin offerings (Catalini and Gans, 2018). Finally, Davidson et al. (2018) suggest that rather than being a general-purpose technology, blockchain should be considered an institutional technology with disruptive Schumpeterian consequences for economic systems.

Blockchain technology has several distinctive features. First, blockchain allows for information storage and transmission with no central authority. Technically, it is a distributed database where the information sent by users is verified and grouped in blocks, at regular time intervals, to form a chain secured by cryptography. Second, by extension, blockchain is a distributed database that manages lists of records that are protected against falsification and modification by storage nodes. In other words, it is a distributed and secure record of all the transactions since the establishment of the distributed system. Third, the emergence of public blockchain networks, such as Bitcoin and Ethereum, has allowed the development of this fully digitized technology, which is based on complex and transparent algorithms that combine various computer and cryptographic techniques. Fourth, firms are beginning to develop their own private (or permissioned) blockchains and these initiatives are generating a new business ecosystem which requires a specific - though far from standardized - computer language.

Thus, blockchain is allowing the development of new types of economic activity that require new types of institutions. The traditional firm, market and government mediators are being 
ousted and the disintermediation and automation of many means of exchange and production is eroding the rents previously earned from their roles as trusted third parties.

In the stream of government literature, the European Commission (2019) describes blockchain as a Key Enabling Technology (KETs) of the digital transformation. Positioned micro/nano-electronics and advanced manufacturing technologies, blockchain has the potential to become the basis for innovations in a range of products across all industrial sectors and to drive the development of entirely new industries. Small and Medium Sized Enterprises are expected to account for the majority of future jobs in KETs, including blockchain, as long as they can avoid the innovation gap or 'valley of death' between the moment when ideas are tested and their transformation into innovative goods and services. The European Commission notes, also, that countries and regions able to fully exploit KETs will become the leading advanced and sustainable economies.

The industry literature has a similarly optimistic view of the potential of blockchain in relation to the creation of jobs and skills. Forbes (2018) reports that blockchain is booming in the advanced economies and is linked to exceptional growth of high-skilled jobs. In addition, PwC (2018) maintains that the financial sector is the largest developer and user of blockchain, followed by manufacturing, energy, health, the public sector, distribution and media. Although the US and China are considered the leaders in blockchain technology, the main European urban centres are considered to have potential. However, McKinsey (2018) suggests that blockchain remains an immature technology, related to a nascent market, which is still searching for a clear recipe for success.

\subsection{Schumpeter Mark 1 and Mark 2}


The Schumpeter Mark 1 and Mark 2 literature includes work that focuses on disruptive technologies and paradigm shifts and their impacts on the emergence and evolution of industries (Dosi, 1982; Sutton, 1998). According to Malerba and Orsenigo (1995, 1997), Schumpeter Mark 1 is characterized by 'creative destruction', ease of entry and the emergence of new firms based on business opportunities, which challenge the incumbents and continuously disrupt current modes of production, organization and distribution. They consider Schumpeter Mark 2 as characterized by 'creative accumulation', the relevance of industrial R\&D laboratories and the key role of large firms. The authors also apply the labels 'widening' and 'deepening' to these patterns: widening applies to an innovative base that is continuously growing; deepening describes accumulation strategies based on existing technological premises.

Industrial dynamics approaches in line with the notion of creative destruction, insist that disruptive technology is driven mostly by new companies and start-ups (Klepper, 1997), which are seen as first movers leading to the emergence of a new industry. Thus, companies based on disruptive technologies tend to be young and small (Geroski, 1995; Sutton, 1998). Geroski (1995) emphasizes, also, that de novo entrants are the most common type of new firms, but that, on average, they are less successful than firms that enter via diversification which are often larger sized at entry. Support from a corporate parent operating in another market is advantageous for entry by diversification. Schumpeter Mark 1 evolution seems linked to new market entry based on the introduction of radical or disruptive innovations while Schumpeter Mark 2 is linked to lack of new entry and technological stagnation, barriers to entry and a stable oligopoly composed of mature established and large firms. Since disruptive firms (Schumpeter Mark 1 type) initiate major technological change, they tend to exhibit faster growth (larger salaried workforce and larger turnover) or even 
exceptional growth (i.e., gazelles; see Coad et al., 2014; Colombelli et al., 2014, 2019) compared to other firms. They are seen as competence enhancing with the ability to exploit constantly increasing innovation opportunities (Tushman and Anderson, 1986; Malerba and Orsenigo, 1997). These disruptive enterprises can become markers that distinguish yesterday's jobs from the jobs of tomorrow and which bring profound changes to skills and employment through persistent new job creation and re-skilling (Autor, 2015; Napoletano and Nesta, 2016) or polarization of skills (Autor and Dorn, 2013). In contrast, Schumpeter Mark 2 firms exhibit incremental technological change, characterized by a strengthening of the synergies among existing innovation opportunities, leading often to competence destruction and job losses (Tushman and Anderson, 1986).

Disruptive Mark 1 companies are most frequent in high-tech sectors (Vivarelli, 1995; Colombelli et al., 2016) and it has been argued that, compared to firms in low-tech manufacturing and traditional services, new technology-based firms in high-tech manufacturing and ICT services sectors drive entrepreneurship. Mark 1 firms tend to display different product innovation characteristics and operate in conditions of high uncertainty induced by the emergence of new industrial sectors and relying, predominantly, on trial and error development. In contrast, Mark 2 firms draw on their experience, which reduces uncertainty and allows choices related to innovation in a mature and stable industry, based on the exploitation of a smaller set of possibilities (Acs and Audretsch, 1990; Audretsch, 1995; Colombo et al., 2004; Colombo and Grilli, 2010).

In terms of the geographic aspects of innovation, Breschi (2000) suggests that there are certain regularities in the sectoral and spatial patterns of technological activities. In addressing the widening versus deepening distinction, Breschi emphasizes that different 
configurations can be observed. In the case of Mark 1 firms, the configuration takes the form of either a 'widening and concentrated pattern' with high and persistent concentration at the spatial level combined with low concentration, SMEs, high levels entry and weak stability at the sectoral level, or a 'widening and diffused pattern' characterized by low concentration at the spatial level and low concentration, SMEs, high levels of entry and poor stability at the sectoral level. The literature supports the idea that companies that develop disruptive technologies are often geographically concentrated. For instance, Autor (2019) highlights that the share of employment of skilled workers is concentrated in cities with high population density, while Klepper (2007) points to the cumulated technological competences in highly innovative sectors within local contexts such as semi-conductors in the Silicon Valley and the automobile industry in Detroit (see also Klepper, 2007, 2010; Buenstorf and Klepper, 2009; Klepper and Simons, 2000). For Mark 2 firms, the alternatives are a 'deepening and concentrated pattern' with high and persistent concentration at the spatial level and high concentration, large size, low entry and high stability at the sectoral level or a 'deepening and diffused pattern' involving low spatial concentration combined with high concentration, large size, low entry and high stability (Breschi, 2000).

\subsection{Summing up}

The literature review and the arguments presented above suggest that the Schumpeterian Mark 1 model provides a better analytical framework since it accommodates many of the characteristics of blockchain technology (see Table 1).

INSERT TABLE 1 ABOUT THERE 
If blockchain technologies are a Schumpeter Mark 1 disruptive technology, chances are that, regardless of firm age, the search for blockchain skills cannot draw upon existing work experience for at least two reasons. First, blockchain skills are entirely new for all industries and we can expect them to reside in the population of newly qualified graduates and young talents at the frontier of knowledge, necessarily with little or no work experience. These talents being external to most of the existing industrial structure, they will be required to start from scratch on the development of new projects, such as peer-to-peer storage and transmission of information or decentralized systems of transactions secured by blocks using crypto assets. Thus, blockchain is likely, primarily, to be built on combinations of entirely new competences rather than the accumulation of extant experience which characterizes traditional industries at mature stages of development. Second, blockchain technology represents a new transaction means and a new business organization. It allows the development of automated tasks, including non-routine ones such as smart contracts, which are self-executed with no central authority which challenges existing governance structures. Blockchain technology depends on new knowledge and specific education and training to produce employees capable of working in flat, decentralized rather than hierarchical organizations which tend to be based on a wide spectrum of experience and skills.

In the next section, we investigate whether Schumpeter Mark 1 or Schumpeter Mark 2 predominates in blockchain industrial dynamics.

\section{Data and methodology}

\subsection{Data collection}


This research was hampered by the non-availability of data, in a statistical-friendly format, on job offers, which required us to build a database. We collected information on blockchain job offers and skills published online to characterize blockchain industrial dynamics. The use of social networks to collect information about employers and potential employees has increased in recent years (Nikolaou, 2014; Zide et al., 2014). In this perspective, we used the Glassdoor website to collect blockchain job offers. ${ }^{1}$ Glassdoor is one of the top websites used to recruit blockchain employees (Rakesh, 2018) and recently reported a near 300\% increase in searches for talent related to cryptocurrencies and blockchain. The job offers originate from all over Europe, which allows international comparison of blockchain job offers across countries such as France and Germany. Each job advertised includes a detailed profile of the firm, which allowed systematic collection of relevant information.

Data collection extended over January to April 2019. The key search term for offers from France and Germany was 'blockchain'; this yielded a large number of advertisements for jobs in both countries over the period of study. The terms 'cryptocurrencies' and 'crypto-assets' represent a sub-section of blockchain technology specific to the financial sector; the term 'distributed ledger technology' refers to broader blockchain content (Hileman and Rauchs, 2017). We discarded job advertisements from head-hunters or temporary employment agencies and considered offers with the same job title, from the same firm, looking for the same experience and posted in the same city to be duplicates.

To facilitate comparison with other fields of activity, we constructed a counterfactual sample corresponding to storekeeping job offers and biotechnology engineering job offers. This counterfactual enhances the interpretation of results about blockchain job offers relative to

\footnotetext{
${ }^{1}$ We initially searched in Linkedln but abandoned this due to the inclusion of inapplicable job adverts, such as secretary in a large IT consulting firm which mentioned the term blockchain. Also, searching on Linkedln was tedious whereas Glassdoor allowed search on keywords and avoided misleading and unproductive searches.
} 
what we consider low technology (storekeeping) and high technology (biotechnology) job offers. To search for low-tech offers, we used the term 'magasinier' for France and 'lagerist' for Germany (both meaning storekeeper in English). For biotechnology job offers, we searched on 'ingénieur biotechnologie' for France and 'biotechnologie ingenieur' for Germany (both meaning 'biotechnology engineer' in English). 


\subsection{Econometric setting}

The main variables are related to the work experience required by firms searching for new skills, regardless of the level of qualification. We consider the four categories of 'internship' meaning that the post required at least some sort of work experience, 'first job' which was considered to be no prior experience required, 'confirmed' and 'manager' - indicating an increasing intensity of work experience required by the firm. Offers were classified as internship when the job offer was explicit about it. Offers that require no experience are considered as 'first job'. When the offer mentioned that the candidate's experience was 'desired', we also consider it as 'first job'. When experience was 'required', we classify the job offer as 'confirmed' job. The category 'manager' involves that the job offer is explicit about the degree of responsibility required. Last, we included new doctoral graduates in the 'first job' category.

Variable $E$ denoting work experience is the variable to be explained in our econometric setting. Since our dependent variable is scored on a Likert scale, we employ maximum likelihood methods to estimate the ordered multinomial probit models. A negative sign indicates a preference for no experience - that is, internship and first job; a positive sign indicates that the job requires some level of experience, i.e. confirmed or manager. The model can be written as:

$$
\operatorname{Pr}\left(E=E_{i}\right)=\prod_{i=1}^{i=4} \Phi(z), \text { avec } z=F(\mathbf{X})
$$

where $\Phi$ is the normal cumulated density function, $i$ is the type of experience required ( $i=1$ : internship; $i=2$ : first job; $i=3$ : confirmed; $i=4$ : manager). The vector $\mathbf{X}$ is composed of six explanatory variables: (i) firm size; (ii) firm age; (iii) firm presence in a 
'superstar' city; (iv) job domain (blockchain, biotechnology, storekeeper); (v) industrial sector; and (vi) geographic location denoted by a series of dummy variables.

\subsection{Explanatory variables}

We now present each of the above explanatory variables.

For variable size, we consider the categories of: (i) micro-firms (fewer than 10 employees); (ii) SMEs (10 to 249 employees); (iii) intermediate firms (250 to 4,999 employees); and (iv) large firms (more than 5,000 employees). We rely on the French Institut National de la Statistique et des Etudes Économiques (INSEE) classification. Size classes can vary across countries, but the above thresholds apply to most of the OECD countries.

As for the age variable, it is accepted that firm entry into the market appears to be relatively easy, as opposed to firm survival that appears substantially more stringent (Geroski, 1995). Therefore, we chose the age thresholds inspired by Acs and Audretsch (1990): (i) between 0 and 2 years, firm exit outweighs firm survival; (ii) between 2 years and 7 years there is a significant increase in the odds of survival; (iii) after 7 years, firm survival outweighs firm exit.

Information on firm size and age was collected from Glassdoor first, and then cross-checked with Linkedln, Wikipedia, and in the last resort kompass.com, societe.com and firmenwissen.com, using firm identification codes. For firms experiencing variations in size related to seasonal employment, we considered the full-time equivalents. If a job offer was from a firm that was part of a group, we assumed it referred to employment in the group (e.g., a job at Citroën was categorized as a job offer from Peugeot Société Anonyme) and 
firm size and year of establishment refer to the group. ${ }^{2}$ We believe that this crossreferencing of information reduces the possibility of inconsistent information.

Since larger cities tend to have larger pools of qualified labour (Autor, 2019), we retrieved information on the firm's location and linked job offers to the nearest large city. For example, a job advertised as being in Labège was assigned to the geographically proximate city of Toulouse. In the case of cities whose small size meant they did not figure on Google maps, (e.g., such Le Petit-Quevilly, a small city on the outskirts of Rouen), we classified it as 'Other'. We applied this rule to both France and Germany. In the case that the job offer only indicated the country, we classified it as 'Undefined' (for both France and Germany).

The industry variables refer to the area of activity, such as 'Finance', which includes commercial banks and fintech firms (e.g., the German Micobo). The 'Consulting' variable includes auditing and consulting firms, such as PricewaterhouseCoopers (PwC). 'Information Technology' includes multinationals such as IBM. 'Manufacturing' includes Biomérieux and Bayerische Motoren Werke (BMW). The variable 'Other' includes less frequent observations such as education, science, telecommunications, tourism, video games and retail. Blockchain, biotechnology and low-tech jobs offers are dispersed among these industry categories.

INSERT TABLE 2 ABOUT THERE

\footnotetext{
${ }^{2}$ We acknowledge that this technique could lead to size bias since firms corresponding to the intermediate category could potentially appear in the data as large firms. In terms of age, the effect seems much more marginal although still possible in cases of takeovers of start-ups by larger firms.
} 
The overall sample consists of 385 job offers: 184 in France and 201 in Germany. The two counterfactual groups include 88 biotechnology job offers and 89 storekeepers offers in France and Germany. These job offers stem from 285 companies and there are some of them which are multinational, therefore we obtain 145 firms located in France and 149 firms are in Germany. The average age of firms corresponds to 60 years with a mean size of 38,000 employees. ${ }^{3}$ The median size is 1,650 employees, meaning that the job offers are posted by intermediate and large sized firms. There are also country differences related to median size: this is 2,300 employees in France and only 1,200 employees in Germany. A student $t$ test (not reported here) rejected the alternative hypothesis of significant differences in firm size and age between the two countries.

In terms of geographical area, we observe that $47.8 \%$ of job offers are for locations in France (Table 3). This difference from the average suggests a larger blockchain job market in Germany. Regarding the centre-periphery balance, we set an arbitrary threshold of 10 job offers to identify the city as a superstar city. This identified two French cities: Lyon with 10 offers and Paris with 79 job offers; and three German cities: Berlin with 21 offers, Frankfurt with 16 offers and Munich with 23 offers.

INSERT TABLE 3 ABOUT THERE

\footnotetext{
${ }^{3}$ This is the direct result of our sampling procedure: because job offers reflect the structure of employment in terms of firm size, the probability of a job offer being posted by a large company is higher than the share of large firms in the economy. Also, it is possible that the cost of posting a job offer on a website might constitute a barrier for smaller firms and might advantage larger firms.
} 
There is a clear gap between the two countries in terms of geographical concentration of jobs. Paris stands out as a leader with half of the sampled offers for France linked to this city, while for Germany the spatial distribution of job opportunities is more balanced. This result is supported further if we include the blockchain offer categories linked to cities that do not appear on Google Maps because of their small size (using scale $100 \mathrm{~km}$ on the map). In this case, we observe only 1 French city, but 24 German cities.

If we consider the industrial structure in the two countries (Table 4), we observe larger shares of offers from consulting firms in Germany (60\%) and from financial sector firms in France (62\%). In the categories of Other, Manufacturing industry and Information technology, the distribution across countries is more balanced.

\section{INSERT TABLE 4 ABOUT THERE}

The offers for posts in superstar cities are related, mostly, to three sectors: Consulting (63\%), Financial (67\%) and Information technology (58\%). Also, these three categories include the majority of blockchain jobs and skills, with $87 \%$ of offers from consulting firms and $95 \%$ from finance and information technology firms combined. Most blockchain jobs are in consulting firms (54 offers) and information technology firms (82 offers), which two sectors account for $65 \%$ of the 208 blockchain jobs.

Before presenting the results, we explore the relationship between the realm of activities of the job offers (blockchain, biotech) and the type of occupation, where the latter includes consultant, salesman, engineer and scientific. We do not make use of this information in the 
econometrics model since it is closely linked to the level of experience required for the job. Moreover, storekeeper is a distinct occupation and we exclude low-technology job offers from the cross-tabulation. We find that the two realms of activities 'blockchain, biotech' are fairly evenly spread across the spectrum of occupations. However, we observe an excess of blockchain job offers as consultant, whereas biotechnology job offers belong to the more qualified end of the spectrum.

INSERT TABLE 5 ABOUT THERE

In summary, blockchain jobs are high skilled jobs and are related mostly to the consulting and information technology sectors where we find more than half of blockchain job offers. Also, blockchain accounts for $49 \%$ of the variance in the industrial sector with an $\mathrm{F}$ value of 93.40, making it the most discriminant explanatory variable (Table 6). The second and third most important explanatory variables refer to low-tech jobs (22\%) and biotechnology sector jobs (22\%); firm age (18\%) and superstar city (17\%) show the least significance and variance related to industrial sector. This suggests that we need to examine the effects on the intensity of the profiles in order to narrow down the type of skills being sought by firms.

\section{Econometric results}

Based on the results from the first model (Table 6), we observe that all size category variables have positive parameters, which for SMEs corresponds to 0.458 at the $10 \%$ level of significance; the other variables are insignificant. This shows that companies in the micro 
firm category tend to recruit more inexperienced workers compared to larger firms. If we include the blockchain job variable, the parameter estimate for superstar city becomes positive (0.306) and significant at the $5 \%$ level. This supports the idea that job opportunities for qualified and experienced people are concentrated in major cities (Autor, 2019). The estimates for blockchain jobs are negative $(-0.541)$ and significant at the $1 \%$ level, while the estimates for biotechnology jobs are positive $(0.324)$ and significant at $5 \%$. In other words, firms offering blockchain jobs tend to look for inexperienced labour with unique new skills. This finding is in line with the fact that blockchain technology involves new computer programming languages which are competence enhancing and result in a new technological paradigm (Tushman and Anderson, 1986; Autor, 2019). These firms are searching for young, low-cost talent (internship experience) at the beginning of their career (first job).

INSERT TABLE 6 ABOUT THERE

When information on industrial sectors is introduced, variable significance remains unchanged at $5 \%$ for superstar cities with a positive sign (0.294), while blockchain jobs are associated with a negative sign $(-0.849)$ at the $1 \%$ significance level. Estimates related with industrial sector are based on a comparison with the category 'Other' and are all positive (Consulting 0.500 , Finance 0.618 and Information technology 0.488 ) and significant at the $5 \%$ level. These sectors prefer some level of experience, which is consistent with their location in a superstar city with a good supply of highly skilled personnel. The sectoral estimates confirm the particularity of blockchain jobs since firms looking for blockchain skills are interested, primarily, in young talent with little professional experience. 
But how large are these effects? Table 7 presents the predicted probabilities, considering all the variables at their sample means and setting the variable of interest at specific values. We decided to integrate biotechnology engineering jobs in our analysis since they are at the borderline of significance. Table 8 displays the changes in the predicted probabilities and provides a quantification of the marginal effects of the variable of interest. If we take the example of superstar city, the models predict that the probability of offering an internship position ranges from 0.176 for a post in a superstar city to 0.261 otherwise. In other words, the probability that the job offer concerns an internship increases by 10 percentage points for more remote geographic areas. ${ }^{4}$ An internship can be considered an additional probationary period and suggests that the lack of skilled workers in high-tech sectors induces firms in superstar cities to recruit this type of job category. In the case of the SME variable, we see that the results are close to be identical to what has just been explained. The model predicts that the probability of offering an internship position ranges between 0.139, if the job offer is from a firm in this size category, to 0.261 , for the micro firm, intermediate sized and large firm categories. Biotechnology engineer shows a similar trend; internship job offers correspond to a probability of 0.172 and a probability of 0.243 otherwise. Interestingly, the sharpest marginal effects are related to the blockchain variable. The results show that the probability that the job offer concerns an internship is multiplied by 3 (from $11.3 \%$ to $35.9 \%$ ), whereas the probability that the blockchain position is for a manager is divided by a factor of 5 . By and large, these results support the idea that blockchain positions tend not to be managerial positions, which contrasts with the idea of more human capital-intensive skills being located at the top of the management structure.

\footnotetext{
${ }^{4}$ Note that the sum of all the probabilities in a given row amounts to unity.
} 
Interestingly, in the case of France, the probability of offering an internship position is 0.255 and decreases to 0.201 for Germany.

\section{INSERT TABLE 7 ABOUT THERE}

Next, we check whether our results are country-specific or hold regardless of the country of the job offer. To do so, we interact all the explanatory variables except the sector dummies, with the dummies for France and Germany (see Table 8).

The results show that the respective estimates for French (0.092) and German (0.877) large firms are positive and that the latter are significant at $10 \%$. Thus, German large firms seem to be looking for more experienced talents than their French counterparts. The results for the age variable are negative $(-0.272)$ for German firms and significant at $5 \%$ which suggests that older, established German firms tend not to search for experience. This might be related to the intrinsic characteristics of the industry structure, which are specific to each country. French job offers specify less experience, although this result is not robust to the introduction of the sector dummies. Also, the majority of jobs advertised for France are linked to superstar cities $(0.420$, significant at the $10 \%$ level), confirming the leading role of Paris for France.

INSERT TABLE 8 ABOUT THERE 
When the sector dummies are included, the results show that French superstar city firms prefer candidates with more experience - positive sign (0.404). The estimates with the blockchain job variable are negative and significant at $1 \%$ for both Germany $(-1.099)$ and France $(-0.855)$. Similar to the first model, we see that firms advertising blockchain jobs look for new skills and new talents with little experience, with knowledge of new computer languages related to the challenges of the blockchain. Again, blockchain job adverts seem to be aimed at less experienced individuals although in categories where most jobs require a certain level of experience in other industries.

\section{Discussion and conclusions}

Our investigation of jobs and skills recruitment, using a Schumpeter Mark 1 and Mark 2 analytical framework, identified some important characteristics of blockchain industrial dynamics. Our empirical results show that blockchain has certain commonalities with a Schumpeter Mark 1 model, although some differences suggest that blockchain cannot be categorized as adhering strictly to this model. In particular, it appears that recruiting firms seeking blockchain skills tend to be established firms rather than start-ups which, generally, are considered to conform to a Schumpeter Mark 1 model (Dosi, 1982; Malerba and Orsenigo, 1995, 1997; Klepper, 1997; Geroski, 1995). We found, also, that these large, established firms tend to be looking for highly skilled staff with little professional experience (Tushman and Anderson, 1986; Colombelli et al., 2014; Autor, 2019) and that these characteristics are specific to blockchain skills compared to the counterfactuals of biotechnology engineering (high-tech) and storekeeping (low-tech). Based on our findings and the literature, we suggest that blockchain is a disruptive technology whose development 
requires entry by diversification, involving large, incumbent companies with large amounts of capital and ability to recruit over time (Geroski, 1995), in a context of low visibility on future developments based on this technology, and reaching far from a stage of standardization (Abernathy and Clark, 1985; Afuah and Bahram, 1995; Arora et al., 2016a, 2016b). It seems, also, that this will require a flatter hierarchy and changes to the organizational structure to accommodate blockchain developments.

Our analysis shows that blockchain recruitment is not confined to the financial sector; the spectrum of sectors that are shaping/are shaped by blockchain is larger than predicted by the Schumpeter Mark 1 literature. This outcome reflects recent developments in the blockchain literature which suggest that blockchain is not confined only to Bitcoin, but includes further generations of blockchain technology (such as Ethereum, and has applications related to artificial intelligence and the Internet of things) with large possible applications beyond financial innovations (Davidson et al., 2018; Böhme et al., 2015; Yermack, 2017).

We observed country disparities in industries looking for blockchain skills, and spatial distributions which appear to be country specific. For example, it seems that France is more characterized by spatial concentration than Germany. We observe that superstar cities seem to be playing their role as hubs of blockchain activity, more apparently for Paris than for Berlin, which is more blockchain spatially distributed (Breschi, 2000). This finding is in line with work on new industrial specializations in Europe at the regional (Xiao et al., 2018) and city (Rodriguez-Pose, 2018) levels which draws some future prospects for Europe to become a blockchain technology leader. 
In terms of the organizational and policy implications of our results, the finding that new hires for blockchain jobs are located at the low experience end of the spectrum indicates that the early stages of their career are characterized by intense professional in-house experience. This could lead to their being trapped in firm specific jobs and experience which suggests, among other things, the need for new blockchain graduate and other training programmes and lifelong learning, which would allow more job mobility.

Our analysis shows that blockchain recruiters are predominantly established firms, with hierarchical structures that might be difficult to change. Blockchain recruitment implies the need for a flatter organizational structures and a new division of labour with more autonomy for new hires, and development of more decentralized work practices. This could support new, transversal industrial policies in the future for the development of blockchain activities and, in a more short-term scenario, new governance principles to adapt firms to the blockchain challenges both in terms of human resources and organisational structures. Indeed, this paper argues that blockchain has the characteristics of a general purpose technology and, as a consequence, all the effects discussed above should not be restrained to a limited number of industrial sectors like finance but rather might also have large scale, inter-sectorial effects.

Our analysis did not identify a unique pattern for blockchain developments: France and Germany exhibit distinct geographic concentration patterns although this might reflect the distribution of economic activities in these countries. However, it would seem reasonable to expect that blockchain developments will have implications for territorial policy. The characteristics of blockchain technology suggest that it is likely to spread from regions offering blockchain related education to more remote locations. 
This paper provides an exploratory study of a new issue. It contributes to the literature by characterizing the industrial dynamics underlying blockchain, using original data. We show which firms are interested in the technology, where are they located and the types of jobs being created. It allows preliminary definition of the expected economic impact of blockchain and some directions for and problems related to future work in this area. 


\section{References}

Abernathy, W., and Clark, K. 1985. Innovation: Mapping the winds of creative destruction. Research Policy. 14(1), 3-22.

Acemoglu, D., and Restrepo, P. 2017. Robots and Jobs : Evidence from US Labor Markets. NBER Working Paper 23285. Cambridge, MA.

Acemoglu D., and Autor, D. 2012. What Does Human Capital Do? A Review of Goldin and Katz's The Race between Education and Technology. Journal of Economic Literature. 50(2), 426-63.

Acs, Z. J., and Audretsch, D. 1990. Innovation and Small Firms. Cambridge, MA: MIT Press.

Afuah, A., Bahram, N. 1995. The hypercube of innovation. Research Policy. 24(1), 51-76.

Alcacer J., Cantwell, J., and Piscitello, L. 2016. Internationalization in the information age: A new era for places, firms, and international business networks? Journal of International Business Studies. 47(5), 499-512.

Antonelli., C., Foray, D., Hall, B., and Steinmueller, E. (ed.) 2006. New frontiers in the economics of innovation and new technology. Cheltenham: Edward Elgar Publishing.

Arora, A., Athreye, S., and Huang, C. 2016a. The paradox of openness revisited: Collaborative innovation and patenting by UK innovators. Research Policy. 45(7), 1352-1361.

Arora, A., Cohen, W.M., and Walsh J.P. 2016b. The acquisition and commercialization of invention in American manufacturing: Incidence and impact. Research Policy. 45(6), 1113-1128.

Atalay, E., Phongthiengtham, P., Sotelo, S., and Tannenbaum, D. 2018. New Technologies and the Labor Market. Journal of Monetary Economics. 97, 48-67.

Audretsch, D. 1995. Innovation and Industry Evolution. Cambridge, MA: MIT Press.

Autor, D. 2015. Why Are There Still So Many Jobs? The History and Future of Workplace Automation. Journal of Economic Perspectives. 29(3), 3-30.

Autor, D. 2019. Work of the Past, work of the Future. NBER Working Paper $n^{\circ} 25588$.

Autor, D., and Dorn, D. 2013. The Growth of Low-Skill Service Jobs and the Polarization of the US Labor Market. American Economic Review. 103(5), 1553-1597.

Autor, D., Katz, L., and Krueger, A. 1998. Computing inequality: have computers changed the labor market? Quarterly Journal of Economics. 113(4), 1169-1213.

Böhme, R., Christin, N., and Edelman, B. 2015. Bitcoin: economics, technology and governance. Journal of Economic Perspectives. 29(2), 213-238.

Breschi, S. 2000. The geography of innovation: a cross sector analysis. Regional Studies. $34(3), 213-229$.

Brynjolfsson, E., and McAfee, A. 2014. The Second Machine Age: Work, Progress, and Prosperity in a Time of Brilliant Technologies. New York: W. W. Norton \& Company. 
Buenstorf, G., and Klepper, S. 2009. Heritage and agglomeration: The Akron tyre cluster revisited. Economic Journal. 119, 705-733.

Catalini, C., and Gans, J. 2016. Some simple economics of the blockchain. NBER Working Paper $n^{\circ} 22952$.

Catalini, C., and Gans, J. 2018. Initial Coin Offerings and the Value of Crypto Tokens. NBER Working Paper $n^{\circ} 24418$.

Coad, A., Daunfeldt, S., Hölzl, W., Johansson, D., and Nightingale, P. 2014. High-growth firms: introduction to the special section. Industrial and Corporate Change. 23(1), 91-11.

Colombelli, A., Krafft, J., and Quatraro, F. 2014. High Growth Firms and Technological Knowledge: Do gazelles follow exploration or exploitation strategies? Industrial and Corporate Change. 23(1), 261-291.

Colombelli, A., Krafft, J., and Quatraro, F. 2019. Firm's growth, green gazelles and ecoinnovation: evidence from a sample of european firms, Small Business Economics Journal, Doi: 10.1007/s11187-019-00236-8.

Colombelli, A., Krafft, J., and Vivarelli, M. 2016. Innovative start-ups. Small Business Economics Journal. 47(2), 1-15.

Colombo, M. G., and Grilli, L. 2010. On Growth Drivers of High-tech Start-ups: Exploring the Role of Founders'Human Capital and Venture Capital. Journal of Business Venturing. 25 (6), 610-26.

Colombo, M. G., Delmastro, M., and Grilli, L. 2004. Entrepreneurs' Human Capital and the Start-up Size of New Technology-based Firms. International Journal of Industrial Organization. 22 (8-9), 1183-211.

Cong, L.W., and He, Z. 2019. Blockchain Disruption and Smart Contracts. The Review of Financial Studies. 32 (5), 1754-1797.

Consoli, D., Vona, F., and Rentocchini, F. 2016. That Was Then, This Is Now: Skills and Routinization in the 2000s. Industrial and Corporate Change. 25 (5), 847-866.

Davidson, S., De Filippi, P., and Potts, J. 2018. Blockchains and the economic institutions of capitalism. Journal of Institutional Economics. 14(4), 639-658.

Dosi, G. 1982. Technological paradigms and technological trajectories: A suggested interpretation of the determinants and directions of technical change. Research Policy. 11(3), 147-162.

European Commission. 2019. https://ec.europa.eu/growth/industry/policy/key-enablingtechnologies/description en.

Forbes. 2018. Bitcoin and blockchain jobs in the U.S. are surging, Oct 18.

Geroski, P.A. 1995. What do we know about entry ? International Journal of Industrial Organization. 13(4), 421-440.

Hileman, G., and Rauchs, M. 2017. Global Blockchain Benchmarking Study. link: https://ssrn.com/abstract=3040224. 
Klepper, S. 1997. Industry life cycle. Industrial and Corporate Change. 6(1), 145-182.

Klepper, S. 2007. Disagreements, spinoffs, and the evolution of Detroit as the capital of US automobile industry. Management Science. 53(4), 616-631.

Klepper, S. 2010. The origin and growth of industry clusters: the making of the Silicon Valley and Detroit. Journal of Urban Economics. 67(1), 15-32.

Klepper, S., and Simons, K.L. 2000. Dominance by birthright: entry of prior radio producers and competitive ramifications in the U.S. television receiver industry. Strategic Management Journal. 21, 997-1016.

Malerba, F., and Orsenigo, L. 1995. Schumpeterian patterns of innovation. Cambridge Journal of Economics. 19(1), 47-65.

Malerba, F., and Orsenigo, L. 1997. Technological regimes and sectoral patterns of innovative activities. Industrial and Corporate Change. 6(1), 83-118.

McKinsey. 2018. https://www.mckinsey.com/business-functions/mckinsey-digital/ourinsights/blockchain-beyond-the-hype-what-is-the-strategic-business-value\#.

Napoletano, M., and Nesta, L., 2016. The multifaceted evolution of industries: sectoral and firm-level evidence. Industrial and Corporate Change. 25(5), 809-812.

Nedelkoska, L. and Quintini G. 2017. Automation, Skills Use and Training. OECD Social, Employment and Migration Working Papers, No. 202, OECD Publishing, Paris.

Nikolaou, I., 2014. Social Networking Websites in Job Search and Employee Recruitment. International Journal of Selection and Assessment. 22(2), 179-189.

PwC. 2018. Blockchain is here. What's your next move? https://www.pwc.com/blockchainsurvey.

Rakesh, S. 2018, The Blockchain Job Market Is Booming. Investopedia, Nov 1st.

Rindfleisch, A., O'Hern, M., and Sachdev, V. 2017. The Digital Revolution, 3D Printing, and Innovation as Data. Journal of Product Innovation Management. 34(6), 681-690.

Rodriguez-Pose, A. (2018). The revenge of the places that don't matter (and what to do about it). Cambridge Journal of Regions, Economy and Society. 11(1), 189-209.

Spitz-Oener, A. 2006. Technical Change, Job Tasks, and Rising Educational Demands: Looking Outside the Wage Structure. Journal of Labor Economics. 24 (2), 235-270.

Sutton, J. 1998. Technology and Market Structure. MIT Press.

Tushman, M. L., and Anderson, P., 1986. Technological discontinuities and organizational environments. Administrative Science Quarterly. 31(3), 439-465

Varian, H. 2018. Artificial Intelligence, Economics, and Industrial Organization, NBER Working Papers $n^{\circ} 24839$.

Vivarelli, M. 1995. The economics of technology and employment. Edward Elgar Publishing.

Xiao, J., Boschma, R. and Andersson, M. 2018. Industrial diversification in Europe: the differentiated role of relatedness. Economic Geography. 94(5), 514-549. 
Yermack, D. 2017. Corporate governance and blockchains. Review of Finance. 21(1), 7-31.

Zide, J., Elman, B., and Shahani-Denning, C., 2014. LinkedIn and recruitment: how profiles differ across occupations. Employee Relations. 36(5), 583-604. 


\section{TABLES}

Table 1: Blockchain, Schumpeter Mark 1 and Schumpeter Mark 2 (authors' elaboration based on the literature review provided in Section 2)

\begin{tabular}{|c|c|c|}
\hline Blockchain literature & Schumpeter Mark 1 & Schumpeter Mark 2 \\
\hline $\begin{array}{c}\text { Blockchain is a disruptive } \\
\text { technology (Böhme et al., 2015; } \\
\text { Davidson et al., 2018) }\end{array}$ & $\begin{array}{l}\text { Creative destruction } \\
\text { Widening pattern }\end{array}$ & $\begin{array}{l}\text { Creative accumulation } \\
\text { Deepening pattern }\end{array}$ \\
\hline $\begin{array}{l}\text { Blockchain is a job creator and } \\
\text { requires mobilization of highly } \\
\text { skilled jobs and the development } \\
\text { of skills (computer science, } \\
\text { cryptography) (Forbes, 2018; } \\
\text { Yermack, 2017). }\end{array}$ & $\begin{array}{l}\text { Growing firms and high growth } \\
\text { firms } \\
\text { Competence enhancing } \\
\text { Emergence of new, low } \\
\text { experienced skills }\end{array}$ & $\begin{array}{c}\text { Growth stagnation in firms } \\
\text { Competence destroying } \\
\text { Accumulation of experience and } \\
\text { skills }\end{array}$ \\
\hline $\begin{array}{c}\text { Blockchain companies are } \\
\text { generally young and small } \\
\text { (Catalini and Gans, 2016, 2018; } \\
\text { Cong and } \mathrm{He}, 2019 \text { ). }\end{array}$ & $\begin{array}{c}\text { New companies or start ups } \\
\text { Young and small firms } \\
\text { De-novo entrants vs entrants by } \\
\text { diversification } \\
\text { Flat organization }\end{array}$ & $\begin{array}{c}\text { Incumbent firms } \\
\text { Old firms } \\
\text { Large firms } \\
\text { Hierarchical organization }\end{array}$ \\
\hline $\begin{array}{l}\text { Blockchain companies are often } \\
\text { observed in in a narrow set of } \\
\text { sectors (finance) (Yermack, 2017; } \\
\text { McKinsey, 2018; PwC, 2018) }{ }^{\mathrm{a}} \text {. }\end{array}$ & $\begin{array}{l}\text { High tech sectors } \\
\text { Sectors at the age of emergence } \\
\text { and growth }\end{array}$ & $\begin{array}{l}\text { Low tech sectors } \\
\text { Sectors at the age of maturity }\end{array}$ \\
\hline $\begin{array}{l}\text { Blockchain companies are often } \\
\text { geographically concentrated, } \\
\text { especially in large urban centres } \\
\text { (European Commission, 2019). }\end{array}$ & $\begin{array}{l}\text { Spatially diffused vs spatially } \\
\text { concentrated } \\
\text { Access to skilled labour and } \\
\text { spillovers in favour of spatial } \\
\text { concentration }\end{array}$ & $\begin{array}{l}\text { Spatially diffused vs spatially } \\
\text { concentrated }\end{array}$ \\
\hline
\end{tabular}

${ }^{a}$ To the best of our knowledge, the literature does not provide reliable information on whether blockchain companies are more frequent in high-tech or low-tech sectors or in emergent or mature sectors. 
Table 2: Descriptive statistics of the characteristics of the recruiting firm

Firm age Firm size

(in years) (in \# Employees)

Whole sample (385 observations)

Mean

59.91

38128.2

Median

33

1650

Minimum

1

2

Maximum

$100+$

427000

France (184 observations)

Mean

65.196

42497.3

Median

34

2300

Minimum

1

2

Maximum

$100+$

427000

\section{Germany (201 observations)}

Mean 55.075

34128.63

Median

30

1200

Minimum

2

2

Maximum

$100+$

377757

Obs: number of job offers; M: Mean; Me: Median S-D: Standard Deviation; Min: Minimum; Max: Maximum. The student t-test points to no significant differences in size and age between German and French companies. The overall sample consists of 385 job offers, 184 being located in France, and 201 in Germany. These job offers stem from 285 companies and some of them are multinational, 145 being located in France, and 149 in Germany. 
Table 3: Number of jobs by territorial area and category in relation to the size distribution of firms

\begin{tabular}{lcccccccc}
\hline Class. & Block & Other & DEU & FRA & BI. DEU & O. DEU & BI. FRA & O. FRA \\
\hline MICRO & 14 & 7 & 8 & 13 & 3 & 5 & 11 & 2 \\
SME & 55 & 42 & 53 & 44 & 31 & 22 & 24 & 20 \\
ISE & 60 & 66 & 79 & 47 & 42 & 37 & 18 & 29 \\
LE & 79 & 62 & 61 & 80 & 48 & 13 & 31 & 49
\end{tabular}

Class.: French classification of company sizes; Block: blockchain job offers; Other: Other job opportunities; DEU: job offers located in Germany; FRA: job offers located in France; BI. DEU.: blockchain job offers located in Germany; O. DEU: other job opportunities located in Germany; BI. FRA.: blockchain job offers located in France; O. FRA: other job offers located in France. MICRO: micro-firms; SME: Small and Medium-sized Enterprises; ISE: Intermediate-sized Enterprises; LE: Large Enterprises. 
Table 4: Sectoral decomposition of key variables

\begin{tabular}{lcccccccc}
\hline Sector & $\mathrm{N}$ & Block & Low & Bio & Age & SC & Md.Size & FRA \\
\hline IT & 86 & 95.3 & 2.3 & 2.3 & 38 & 58.1 & 550 & 48.8 \\
Cons & 62 & 87.1 & 0 & 12.9 & 27 & 62.9 & 852 & 40.3 \\
Ind & 138 & 15.2 & 36.2 & 48.6 & 81 & 19.6 & 3300 & 45.7 \\
Finance & 21 & 95.2 & 0 & 4.8 & 64 & 66.7 & 350 & 61.9 \\
Other & 78 & 39.7 & 47.4 & 12.8 & 73 & 24.4 & 1100 & 52.6 \\
\hline Mean (total) & 385 & $54.2(208)$ & $23.2(89)$ & $22.9(88)$ & 59.9 & 38.7 & 1650 & $47.8(184)$ \\
F-test & & 93.40 & 26.99 & 26.54 & 21.11 & 18.94 & 4.42 & 1.01 \\
$\mathrm{R}^{2}$ & & 0.496 & 0.221 & 0.218 & 0.181 & 0.166 & 0.045 & 0.011
\end{tabular}

$\mathrm{N}$ : number of job offers; Block: share in job offers related to blockchain technology; Low: share in job offers related to lowtech jobs; Bio: share in job offers of biotechnology engineer's job; Age: average age of firms; SC: cumulated share of employment in superstar cities; Md.Size: median size of firms; FRA: share of job offers in France. IT: Information Technology; Cons.: Consulting firm; Ind.: Manufacturing; Finance: Financial Industry; Other: Other industries. 
Table 5: Cross-tabulation of occupation with the realm of activities, excluding storekeepers $(N=296)$.

\begin{tabular}{lccc}
\hline Function & Blockchain job & Biotech job & Total \\
\hline Commercial & 9 & 6 & 15 \\
Consultant & $(10.5)$ & $(4.5)$ & \\
& 69 & 9 & 78 \\
Engineer & $(54.8)$ & $(23.2)$ & 181 \\
& 118 & 63 & \\
Scientific & $(127.2)$ & $(53.8)$ & 22 \\
& 12 & 10 & 296 \\
\hline
\end{tabular}

Pearson Chi-Square (3): 17.95 Pr $=0.000$. Expected frequencies In parentheses. 
Table 6: The determinants of work experience searched. Ordered multinomial Probit Model.

Variable

Work experience searched

Small and medium-sized firms

$0.458^{*}$

$0.464^{*}$

$0.489 *$

$0.446^{*}$

(0.266)

(0.266)

(0.267)

(0.269)

Intermediate-sized firms

0.195
$(0.277)$

0.204

0.213

0.135

(0.277)

(0.278)

(0.282)

(0.286)

Large firms

0.198

0.198

0.365

0.331

(0.298)

(0.298)

(0.306)

(0.309)

Firm age

$$
0.007
$$

0.007

$-0.089$

$-0.053$

(0.065)

(0.065)

(0.069)

(0.070)

Superstar cities

$$
0.010
$$

(0.119)

0.002

(0.121)

$0.306 * *$

$0.294 * *$

(0.142)

(0.143)

French job offers

0.044

(0.113)

$-0.139$

$-0.178$

(0.120)

(0.123)

Blockchain skill

$-0.541 * * *$

(0.172)

$-0.849 * * *$

$0.324 * *$

(0.212)

Biotechnology engineer

(0.165)

0.250

(0.170)

Consulting

Finance

Manufacturing

0.126

(0.164)

Information Technology

\begin{tabular}{lcccc}
\hline Observations & 385 & 385 & 385 & 385 \\
LL & -494.7 & -494.6 & -479.6 & -475.2 \\
LRchi2 & 5.307 & 5.461 & 35.47 & 44.23 \\
\hline
\end{tabular}

Cut-off points omitted for clarity. Standard errors in parentheses. $p<0.01, * * p<0.05, * p<0.1$. The unreported reference category is 'micro-firms', defined as firms with less than 10 employees. A small and medium-sized firm - 10 to 249 employees; intermediate-sized firm 250 to 4,999 employees; large firm more than 4,999 employees. 
Table 7: Marginal effects on the probability of a job offer to belong to a given category of work experience

\begin{tabular}{|c|c|c|c|c|c|}
\hline & Internship & First Job & Confirmed & Manager & Results $1^{\text {st }}$ Model \\
\hline \multicolumn{6}{|c|}{ Superstar cities } \\
\hline Yes & 0.176 & 0.361 & 0.352 & 0.111 & $0.294^{* *}$ \\
\hline Not & 0.261 & 0.389 & 0.285 & 0.065 & $(0.143)$ \\
\hline Diff $p r$ & 0.085 & 0.028 & -0.067 & -0.046 & \\
\hline \multicolumn{6}{|c|}{ Small and medium-sized firms } \\
\hline Yes & 0.139 & 0.337 & 0.382 & 0.142 & $0.446 *$ \\
\hline No & 0.261 & 0.389 & 0.286 & 0.065 & $(0269)$ \\
\hline Diff $p r$ & 0.122 & 0.052 & -0.096 & -0.077 & \\
\hline \multicolumn{6}{|c|}{ Biotechnology engineer } \\
\hline Yes & 0.172 & 0.360 & 0.355 & 0.113 & 0.250 \\
\hline Not & 0.243 & 0.386 & 0.298 & 0.072 & $(0.170)$ \\
\hline Diff $p r$ & 0.071 & 0.026 & -0.057 & -0.041 & \\
\hline \multicolumn{6}{|c|}{ Blockchain skill } \\
\hline Yes & 0.359 & 0.388 & 0.217 & 0.036 & $-0.849 * * *$ \\
\hline Not & 0.113 & 0.313 & 0.402 & 0.172 & $(0.212)$ \\
\hline Diff $p r$ & -0.246 & -0.075 & 0.185 & 0.136 & \\
\hline \multicolumn{6}{|c|}{ French job offers } \\
\hline Yes & 0.255 & 0.388 & 0.290 & 0.067 & -0.178 \\
\hline No & 0.201 & 0.373 & 0.332 & 0.094 & $(0.123)$ \\
\hline Observations & 385 & 385 & 385 & 385 & 385 \\
\hline LL & & & & & -475.2 \\
\hline LRchi2 & & & & & 44.23 \\
\hline
\end{tabular}

Standard errors in parentheses. $\mathrm{P}<0.01,{ }^{*} * \mathrm{p}<0.05, * \mathrm{p}<0.1$ 
Table 8: The determinants of work experience searched by country. Ordered multinomial Probit Model.

\begin{tabular}{|c|c|c|c|c|}
\hline & Germany & France & Germany & France \\
\hline Small and medium-sized firms & $\begin{array}{c}0.529 \\
(0.418)\end{array}$ & $\begin{array}{c}0.484 \\
(0.356)\end{array}$ & $\begin{array}{c}0.530 \\
(0.421)\end{array}$ & $\begin{array}{c}0.426 \\
(0.360)\end{array}$ \\
\hline Intermediate-sized firms & $\begin{array}{c}0.381 \\
(0.440)\end{array}$ & $\begin{array}{c}0.170 \\
(0.387)\end{array}$ & $\begin{array}{c}0.332 \\
(0.444)\end{array}$ & $\begin{array}{c}0.099 \\
(0.390)\end{array}$ \\
\hline Large firms & $\begin{array}{l}0.877^{*} \\
(0.507)\end{array}$ & $\begin{array}{l}0.0922 \\
(0.401)\end{array}$ & $\begin{array}{l}0.895^{*} \\
(0.512)\end{array}$ & $\begin{array}{c}0.038 \\
(0.404)\end{array}$ \\
\hline Firm Age & $\begin{array}{c}-0.272 * * \\
(0.107)\end{array}$ & $\begin{array}{l}0.0263 \\
(0.091)\end{array}$ & $\begin{array}{c}-0.218^{* *} \\
(0.110)\end{array}$ & $\begin{array}{c}0.041 \\
(0.093)\end{array}$ \\
\hline Superstar city & $\begin{array}{c}0.247 \\
(0.182)\end{array}$ & $\begin{array}{l}0.420^{*} \\
(0.243)\end{array}$ & $\begin{array}{c}0.239 \\
(0.183)\end{array}$ & $\begin{array}{c}0.404 \\
(0.247)\end{array}$ \\
\hline Blockchain job & $\begin{array}{c}-0.799 * * * \\
(0.249)\end{array}$ & $\begin{array}{l}-0.524 * \\
(0.284)\end{array}$ & $\begin{array}{c}-1.099 * * * \\
(0.279)\end{array}$ & $\begin{array}{c}-0.855^{* * *} \\
(0.317)\end{array}$ \\
\hline Biotechnology job & $\begin{array}{c}0.124 \\
(0.256)\end{array}$ & $\begin{array}{l}0.375^{*} \\
(0.225)\end{array}$ & $\begin{array}{c}0.059 \\
(0.260)\end{array}$ & $\begin{array}{c}0.294 \\
(0.228)\end{array}$ \\
\hline French job offers & & & & \\
\hline Consulting & & & & \\
\hline Finance & & & & \\
\hline Manufacturing & & & & \\
\hline Information Technology & & & & \\
\hline Observations & \multicolumn{2}{|c|}{385} & \multicolumn{2}{|c|}{385} \\
\hline $\mathrm{LL}$ & \multicolumn{2}{|c|}{-476.4} & \multicolumn{2}{|c|}{-472.3} \\
\hline LRchi2 & \multicolumn{2}{|c|}{41.81} & \multicolumn{2}{|c|}{50.14} \\
\hline
\end{tabular}

Cut-off points omitted for clarity. Standard errors in parentheses. $\mathrm{P}<0.01, * * p<0.05, * \mathrm{p}<0.1$. The unreported reference category is micro-firms (less than 10 employees). Small and medium-sized firms (10 to 249 employees); intermediate-sized firms (250 to 4,999) employees; large firms (more than 4,999 employees). 